\title{
Lessons learned: a pilot study on occupational therapy effectiveness for children with sensory modulation disorder.
}

\author{
Lucy Jane Miller \\ University of Colorado at Denver \\ Sarah A. Schoen \\ University of Colorado at Denver \\ Katherine James \\ University of Colorado at Denver \\ Roseann C Schaaf \\ Thomas Jefferson University
}

Follow this and additional works at: https://jdc.jefferson.edu/otfp

Part of the Occupational Therapy Commons

Let us know how access to this document benefits you

\section{Recommended Citation}

Miller, Lucy Jane; Schoen, Sarah A.; James, Katherine; and Schaaf, Roseann C, "Lessons learned: a pilot study on occupational therapy effectiveness for children with sensory modulation disorder." (2007). Department of Occupational Therapy Faculty Papers. Paper 20. https://jdc.jefferson.edu/otfp/20

This Article is brought to you for free and open access by the Jefferson Digital Commons. The Jefferson Digital Commons is a service of Thomas Jefferson University's Center for Teaching and Learning (CTL). The Commons is a showcase for Jefferson books and journals, peer-reviewed scholarly publications, unique historical collections from the University archives, and teaching tools. The Jefferson Digital Commons allows researchers and interested readers anywhere in the world to learn about and keep up to date with Jefferson scholarship. This article has been accepted for inclusion in Department of Occupational Therapy Faculty Papers by an authorized administrator of the Jefferson Digital Commons. For more information, please contact: JeffersonDigitalCommons@jefferson.edu. 


\title{
Occupational Therapy Using a Sensory Integrative Approach: A Case Study of Effectiveness
}

\author{
Roseann C. Schaaf, Kathleen McKeon Nightlinger
}

\section{KEY WORDS}

- effectiveness

- occupational therapy

- pediatric

- sensory integration

- sensory processing
Roseann C. Schaaf, PhD, OTR/L, FAOTA, is Associate Professor, Vice Chairman, and Director of Graduate Programs, Department of Occupational Therapy, Thomas Jefferson University, 130 South Ninth Street, Philadelphia, PA 19107; roseann.schaaf@jefferson.edu.

Kathleen McKeon Nightlinger, MS, OTR/L, is Independent Contractor, Philadelphia; kathnight@verizon.net.
OBJECTIVE. This article presents a case report of a child with poor sensory processing and describes the disorder's impact on the child's occupational behavior and the changes in occupational performance during 10 months of occupational therapy using a sensory integrative approach (OT-SI).

METHOD. Retrospective chart review of assessment data and analysis of parent interview data are reviewed. Progress toward goals and objectives is measured using goal attainment scaling. Themes from parent interview regarding past and present occupational challenges are presented.

RESULTS. Notable improvements in occupational performance are noted on goal attainment scales, and these are consistent with improvements in behavior. Parent interview data indicate noteworthy progress in the child's ability to participate in home, school, and family activities.

CONCLUSION. This case report demonstrates a model for OT-SI. The findings support the theoretical underpinnings of sensory integration theory: that improvement in the ability to process and integrate sensory input will influence adaptive behavior and occupational performance. Although these findings cannot be generalized, they provide preliminary evidence supporting the theory and the effectiveness of this approach.

Schaaf, R. C., \& Nightlinger, K. M. (2007). Occupational therapy using a sensory integrative approach: A case study of effectiveness. American Journal of Occupational Therapy, 61, 239-246.

Crisp $_{\text {resp }}$ hildren with poor sensory processing often have difficulty regulating their responses to sensation. Lane, Miller, and Hanft (2000) described this as sensory modulation disorder, an inability to "regulate and organize the degree, intensity, and nature of response to sensory input in a graded and adaptive manner" (p. 1). Occupational therapy intervention for this population uses principles from sensory integration theory and focuses on engagement in child-directed, sensory-rich experiences that are individually designed to address each child's specific sensory needs (Ayres, 1979). The therapist artfully engineers and adjusts the sensory qualities of the environment, promoting self-direction and play while facilitating adaptive responses in motor, affective, social, language, and cognitive areas; creating the "just-right challenge"; and tapping the child's inner drive (Ayres, 1972; Schaaf \& Smith Roley, 2006). "The goal of intervention is to improve the child's ability to process and integrate sensory information as a basis for enhanced independence and participation in daily life activities, play (including social participation) and school tasks" (Schaaf \& Miller, 2005, p. 2).

The ability to modulate sensory information provides a foundation for meaningful and purposeful participation in a full range of daily occupations, and therefore, people with poor sensory modulation often have problems successfully meeting the challenges of everyday life (Lane et al., 2000). They demonstrate extreme hyporesponsivity or hyperresponsivity to typical levels of sensory input and exhibit 
unusual patterns of sensation seeking or avoiding that impede full participation in everyday activities such as dressing, playing, mealtime, bath time, and social interaction with others (Dunn, 1997). Frequently, extreme emotional states such as anxiety, depression, anger, and hostility also are present (Schaaf \& Smith Roley, 2006). Parents report that poor social participation, self-regulation, and perceived competence are key difficulties experienced by their children (Cohn, Miller, \& Tickle-Degnen, 2000).

Although occupational therapy using a sensory integrative approach (OT-SI) is widely used for children with poor sensory modulation, evidence supporting its value and effectiveness is controversial and inconclusive. Efficacy studies have shown varying results (see Miller [2003] and Mulligan [2003] for reviews) partly due to the heterogeneity of the population, lack of strict adherence to the principles of sensory integration theory and treatment, and use of outcome measures that are not "occupation" based. Given these issues, one strategy for evaluating the effectiveness of intervention for this population is the case study approach. This approach allows the researcher to provide an in-depth analysis of a person's intervention outcomes and changes in behavior as a consequence of intervention and allows the use of multiple methods of data collection to explain the complexity of the case (DePoy \& Gitlin, 1998). Although the case study approach does not allow generalization of findings, it informs clinical practice by explicating clinical problems and useful solutions.

\section{Methods}

A descriptive case study design was used to evaluate the effectiveness of OT-SI. A history and occupational profile (Schaaf \& Smith Roley, 2006) revealed that many of the participant child's presenting problems could be related to sensory avoidance and hypersensitivity to sensation. To further assess this hypothesis, the Sensory Profile (Dunn, 1999), an interview with the parent, a review of previous evaluation reports, and systematic observation of behaviors were performed. Based on assessment data, specific goals were developed and reviewed with the child's mother to assure that the goals were meeting identified and appropriate areas of concern. Documentation of progress toward goals was collected and charted weekly. A parent interview was conducted during the final month of intervention to obtain input about the child's past and present occupational concerns and the success of the OT-SI program in meeting his needs.

\section{Participant}

$\mathrm{J}$ was a 4-year-old male who lived with his parents and older brother in a suburban area. He was born after a full-term pregnancy with no birth or early infancy complications. J's mother described him as a hesitant child who stayed close and rarely wandered or got into things. At about 2 years of age, when J's language lagged, his parents contacted the local early intervention agency and were provided with speech and language therapy, occupational therapy, and educational support services. The focus of intervention was a developmental approach that facilitated skill development through the use of developmentally appropriate activities. In reflecting on J's development, J's mother noted,

The summer that he turned 2 , he stood out ... compared to other kids. He was running around saying the alphabet, that's all he would do. He was completely obsessed with numbers and letters. He could say his ABCs forward and backward, but he couldn't say "Mom, juice." He had a few words that referred to everything. I started to notice ... lots of issues with him, lots of texture aversions. If we were walking in the grass, he would not take two steps forward. He would put his feet in the ground and not move until someone picked him up . . . because he did not like the feel of that. And it just broke our hearts to see him not find joy but fear and major blocks with things that should be normal, everyday, fun childhood play things. (J's mother, personal communication, July 25,2002 )

After 1 year of early intervention, a comprehensive reevaluation found that, although some improvements were noted, J still had substantial needs in his expressive language skills and his overall social, emotional, behavioral, motor, and sensory development. J was still hesitant to participate in new activities and avoided sensory activities, which was affecting his ability to participate in social contexts or to play independently. In addition, J's mother now noticed oral sensory sensitivities as well as movement and auditory sensitivity:

He never explored anything orally. He would never take a pacifier, he absolutely refused to take a bottle. . . . He drooled much longer than a child should . . . and he had major texture aversions to foods. He had such a limited diet, it was scary. I remembered slicing pears and putting them on a plate, and [him] physically start shaking from the texture, and flinging it [across the room].... He never sought out movement. . . . He would not go up or down our stairs. As a parent, it was wonderful: I didn't need any gates, he was scared to death, and he wouldn't explore any of that. Playground was really tough for him. He would circle around and never really climb on anything. Kids would ask him to, he would say no, shut his eyes, and walk away. That was the hardest for me, seeing him struggle so much with something he should be enjoying. [Socially] he never really interacted with a lot of kids. He was so overwhelmed with anyone he didn't know well. He never was the kind of kid that would flip out or get angry; instead, he would shut 
down and he would block out noises and sounds and stimuli that bothered him. (J's mother, personal communication, July 25, 2002)

J's mother decided to seek additional occupational therapy services, specifically OT-SI. The primary therapist was certified in the Sensory Integrative Process by the University of Southern California/Western Psychological Services and had 20 years of experience using the sensory integrative frame of reference as part of her occupational therapy practice.

\section{Measures}

The Sensory Profile (Dunn, 1999) was used to assess J's behaviors and their potential sensory basis. The Sensory Profile is a measure of children's responses to sensory events in daily life that provides data about how patterns in sensory development might be contributing to, or creating barriers to, performance in daily life (Dunn, 1999). The Sensory Profile's content validity is reported at $63 \%$, and construct validity is rated as moderate (see Dunn, 1999, for more details). J scored in the definite difference range on 5 of the 14 category sections and 3 out of 8 factors, and in the probable difference range on 3 of the categories and 2 of the factors as detailed in Table 1. J was not administered the Sensory Integration and Praxis Tests because he was unable to manage the complex directions associated with this test at this time.

\section{Table 1. Sensory Profile Test Scores for J}

\begin{tabular}{lc}
\hline Category/Section & Difference Rating \\
\hline Sensory Processing & \\
Auditory Processing & Probable \\
Visual Processing & Probable \\
Vestibular Processing & Typical \\
Touch Processing & Definite \\
Multisensory & Probable \\
Oral Sensory & Typical \\
Modulation Processing & \\
Sensory Related to Endurance/Tone & Definite \\
Modulation to Body Position/Movement & Definite \\
Modulation of Movement/Activity Level & Typical \\
Modulation of Sensory Input/Emotional & Definite \\
Modulation of Visual Input & Typical \\
Behavioral/Emotional Responses & \\
Emotional/Social Responses & Definite \\
Behavioral Outcomes of Sensory Processing & Probable \\
Thresholds of Responses & Typical \\
Factors & \\
Sensory Seeking & Typical \\
Emotionally Reactive & Definite \\
Low Endurance/Tone & Definite \\
Oral Sensory Sensitivity & Typical \\
Inattention/Distractibility & Typical \\
Poor Registration & Probable \\
Sensory Sensitivity & Definite \\
Sedentary & Probable \\
\hline
\end{tabular}

Goals for therapy were developed in collaboration with J's mother and focused on improving sensory processing as a basis for enhanced ability to participate in everyday activities. In keeping with the theory of sensory integration and the practice guidelines for occupational therapy (American Occupational Therapy Association, 2002), goals were based on assessment findings and focused on occupation-based outcomes and the underlying sensory components that had an impact on these (Mailloux, 2006). J's goals are detailed in Figure 1.

Goal attainment scaling was used to document, quantify, and compare progress on each goal. The system for developing the goal attainment scale followed the recommendations in the literature (Kiresuk, Smith, \& Cardillo, 1994; Mailloux et al., 2007; Ottenbacher \& Cusick, 1990). The rating for each goal for every session was determined by reviewing weekly progress notes to determine the scaled rank.

\section{Assessment Findings}

The occupational therapy assessment of J's strengths and needs indicated that $\mathrm{J}$ demonstrated notable deficits in sensory processing that were affecting his ability to participate optimally in social, play, and home activities. Specifically, he demonstrated hyperresponsivity to tactile, vestibular, oralsensory, and auditory stimuli; a limited food repertoire; exaggerated emotional, behavioral, and fear responses to sensation and everyday activities; and expressive language delays. His occupational therapy report summarized:

$\mathrm{J}$ is a shy and quiet $4 \frac{1}{2}$-year-old child referred for an occupational therapy evaluation to assess sensory integrative and praxis abilities and needs, and to determine if delays in these areas may be affecting his participation in ageappropriate activities. Specifically, his mother notes that he has excessive fear reactions to typical movement/play activities (such as playground equipment), limited strategies for play and interaction with others, a significantly limited food repertoire, and delayed communication skills. He has a supportive family, enjoys ball skills, and demonstrates emerging language and communication skills. $\mathrm{J}$ is interested in play, but is very hesitant and fearful to engage in many gross motor play activities such as climbing and jumping. He primarily uses vision to explore his environment and is a passive, observant child. When coaxed to play, however, and provided with play ideas, J engages hesitantly. Assessment findings indicate that poor sensory processing contributes to described difficulties. Specifically, he demonstrates sensitivity and fear of movement activities, and excessive sensitivity to auditory stimuli and tactile sensations in his mouth and on his body. In addition, he demonstrates a moderate dyspraxia in that he has difficulty creating ideas and schemes for play and movement activities. (R. Schaaf, personal communication, July 28, 2002) 
1. J will demonstrate an increase in sensory and motor skills as a basis for independent participation in age-appropriate home, school, and community activities Measurement: $80 \%$ of the time as observed by the therapist and reported by parents.

\begin{tabular}{|c|c|c|c|c|}
\hline $\begin{array}{l}\qquad-1 \\
\mathrm{~J} \text { requires assistance to } \\
\text { complete a 1-step activity }\end{array}$ & $\begin{array}{l}0 \\
\text { J will request and perform a } \\
\text { simple motor activity }\end{array}$ & \begin{tabular}{l}
\multicolumn{1}{c}{1} \\
$\mathrm{~J}$ will independently request \\
and complete a 2-step \\
sequence
\end{tabular} & \begin{tabular}{l}
\multicolumn{1}{c}{2} \\
J will independently request \\
and complete a 3- to 4-step \\
sequence
\end{tabular} & $\begin{array}{l}\text { 3 } \\
\text { J will independently request } \\
\text { and complete a 4- to 6-step } \\
\text { sequence during session }\end{array}$ \\
\hline
\end{tabular}

2. J will participate in vestibular activities without fear reactivity as a basis for age-appropriate play with peers.

Measurement: $80 \%$ of the time as observed by the therapist and reported by parents.

\begin{tabular}{|c|c|c|c|c|}
\hline $\begin{array}{l}\quad-1 \\
\mathrm{~J} \text { will participate in } 5 \text { min of } \\
\text { vestibular activities during } \\
\text { OT session }\end{array}$ & $\begin{array}{l}\text { 0 } \\
\text { J will participate in } 10 \text { min } \\
\text { of vestibular activities with } \\
\text { support from parent or } \\
\text { therapist during OT session }\end{array}$ & $\begin{array}{l}1 \\
\mathrm{~J} \text { will participate in } 15 \mathrm{~min} \\
\text { of vestibular activities with } \\
\text { support from parent or } \\
\text { therapist during OT session }\end{array}$ & \begin{tabular}{l}
\multicolumn{2}{c}{2} \\
$J$ will participate in 20 min \\
of vestibular activities with \\
minimal support from \\
parent or therapist
\end{tabular} & \begin{tabular}{l}
\multicolumn{1}{c}{3} \\
J will participate in age- \\
appropriate activities that \\
have a vestibular component \\
(swings, playground activi- \\
ties) at home/community \\
settings
\end{tabular} \\
\hline
\end{tabular}

3. J will participate in a variety of oral sensory activities as a basis for expanded food repertoire and increased participation in mealtime and snack time. Measurement: $80 \%$ of the time as observed by the therapist and reported by parents.

\begin{tabular}{|c|c|c|c|c|}
\hline $\begin{array}{l}\quad-1 \\
\mathrm{~J} \text { will refuse to eat nonpre- } \\
\text { ferred food during oral- } \\
\text { motor session }\end{array}$ & $\begin{array}{l}\text { 0 } \\
\text { J will take } 1 \text { bite of nonpre- } \\
\text { ferred food and participate } \\
\text { in oral motor play for } 5 \text { min } \\
\text { during session }\end{array}$ & $\begin{array}{l}1 \\
\mathrm{~J} \text { will participate in oral- } \\
\text { motor play (whistles, bub- } \\
\text { bles) for } 10 \text { min with peer }\end{array}$ & $\begin{array}{l}2 \\
\text { J will choose nonpreferred } \\
\text { food initially during snack } \\
\text { session and will participate } \\
\text { in oral-motor play for } \\
15 \text { min }\end{array}$ & $\begin{array}{l}\text { 3 } \\
\text { J will tolerate preferred/non- } \\
\text { preferred foods interchange- } \\
\text { ably throughout snack ses- } \\
\text { sion and participate in oral- } \\
\text { motor play independently }\end{array}$ \\
\hline
\end{tabular}

4. J will demonstrate improved social development as a basis for participation in play with peers.

Measurement: $80 \%$ of the time as observed by the therapist and reported by parents.

\begin{tabular}{|l|l|l|l|l|}
\hline \multicolumn{1}{|c|}{-1} & \multicolumn{1}{c|}{0} & \multicolumn{1}{c|}{1} & \multicolumn{1}{c}{2} \\
$\begin{array}{l}\mathrm{J} \text { will initiate social interac- } \\
\text { tion with peer with direction } \\
\text { and prompting }\end{array}$ & $\begin{array}{l}\mathrm{J} \text { will initiate 1 social inter- } \\
\text { action with peer during 0T } \\
\text { session }\end{array}$ & $\begin{array}{l}\mathrm{J} \text { will tolerate 15 min of } \\
\text { social interaction with peer }\end{array}$ & $\begin{array}{l}\text { J will have a 10-min conver- } \\
\text { sation with peer during 0T } \\
\text { session }\end{array}$ & $\begin{array}{l}\text { J will initiate 3 or 4 social } \\
\text { situations with peer to pro- } \\
\text { mote social awareness and } \\
\text { interaction }\end{array}$ \\
\hline
\end{tabular}

5. J will demonstrate age-appropriate fine-motor skills as a basis for participation in school activities.

Measurement: $80 \%$ of the time as observed by the therapist and reported by parents.

Cutting/Hand Manipulation/Grip Strength

\begin{tabular}{|c|c|c|c|c|}
\hline $\begin{array}{l}\quad-1 \\
\mathrm{~J} \text { requires moderate physi- } \\
\text { cal assistance to snip paper } \\
\text { and to maintain proper scis- } \\
\text { sor positioning }\end{array}$ & \begin{tabular}{l}
\multicolumn{1}{c}{0} \\
$\mathrm{~J}$ requires minimal physical \\
assistance to snip paper and \\
to maintain proper scissor \\
positioning
\end{tabular} & \begin{tabular}{l}
\multicolumn{1}{c}{1} \\
$\mathrm{~J}$ requires moderate verbal \\
cues to snip paper in proper \\
direction and to maintain \\
proper scissor positioning
\end{tabular} & \begin{tabular}{l}
\multicolumn{1}{c}{2} \\
$\mathrm{~J}$ requires minimal verbal \\
cues to snip paper in proper \\
direction and to maintain \\
proper scissor positioning
\end{tabular} & $\begin{array}{l}\qquad 3 \\
\mathrm{~J} \text { can independently cut } \\
\text { across paper and maintain } \\
\text { proper scissor positioning } \\
\text { throughout }\end{array}$ \\
\hline
\end{tabular}

Hand Strength/Visual Motor Coordination

\begin{tabular}{|c|c|c|c|c|}
\hline $\begin{array}{l}\quad-1 \\
\mathrm{~J} \text { requires maximum assis- } \\
\text { tance in throwing and catch- } \\
\text { ing a ball from } 10 \text {-feet } \\
\text { distance }\end{array}$ & \begin{tabular}{l}
\multicolumn{1}{c}{0} \\
$\mathrm{~J}$ requires moderate assis- \\
tance in throwing and catch- \\
ing a ball from 10 -feet \\
distance
\end{tabular} & $\begin{array}{l}\quad 1 \\
\mathrm{~J} \text { requires minimal assis- } \\
\text { tance in throwing and catch- } \\
\text { ing a ball from } 10 \text {-feet } \\
\text { distance }\end{array}$ & $\begin{array}{l}2 \\
\text { J requires minimal assis- } \\
\text { tance in throwing and catch- } \\
\text { ing a ball from 15-20-feet } \\
\text { distance }\end{array}$ & $\begin{array}{l}\text { 3 } \\
\mathrm{J} \text { can throw and catch a ball } \\
\text { independently from 15-20- } \\
\text { feet distance }\end{array}$ \\
\hline
\end{tabular}

Note. OT = occupational therapy. Each of J's five main goals were ranked and scaled according to the following scale: $-1=\mathrm{J}$ has regressed from his previous treatment session in this particular goal; $0=$ current level of functioning at start of treatment; 1 = reflects incremental progress in the specified goal; $2=$ reflects significant progress in the specified goal; $3=J$ has attained this goal.

Figure 1. Goals and goal attainment scale for J. 
Based on the assessment results, direct OT-SI was recommended once per week with frequent consultation and collaboration with J's mother (weekly) and J's preschool teacher (monthly). Direct, individual therapy was aimed at remediation of the underlying sensory hypersensitivities. Consultation with the teacher was accomplished through the use of phone conversation and a notebook that J's mother relayed to the school weekly. Therapy was provided in an OT-SI clinic consistent with the criteria outlined by Parham and colleagues. (2007), Schaaf and Smith Roley (2006), and Slavik and Chew (1990). A typical treatment session is outlined in Table 2 .

\section{Results}

\section{Goal Attainment Scales}

Visual inspection of J's goal attainment scales (using Excel line graphs) shows that $\mathrm{J}$ attained his target level in each of the 5 occupational therapy goals as depicted in Figure 2. To summarize, J (a) demonstrated improvements in motor planning and participation in age-appropriate activities, (b) decreased fear reactivity to movement (vestibular) activities and participation in age-appropriate playground equipment, (c) decreased oral-sensory sensitivity and expanded his repertoire of food and participation with family and peers at mealtime, (d) improved social development and began to initiate social play with peers, and (e) improved manual exploration and participation in age-appropriate fine and visual-motor and play activities.

J's improvements in his ability to tolerate and process sensory input were striking and apparent in home, community, and clinic environments. His decrease in fear of movement and tactile stimuli set the stage for participation in age-appropriate play, thus enhancing socialization opportunities. During his occupational therapy sessions, he progressed from unwillingness to participate in climbing and movement activities to playfully enjoying such activities. J was observed joyfully playing on swings, climbing up, and participating in a variety of sensorimotor activities. Similarly, he tolerated oral-sensory stimuli and ate a variety of foods, thus enabling him to participate more successfully in mealtime activities.

Table 2. A Typical OT-SI Treatment Session for J

\begin{tabular}{lll}
\hline Activity & Purpose & Example \\
\hline Warm-up & $\begin{array}{ll}\text { To ensure that the child is comfortable } \\
\text { and relaxed for play }\end{array}$ & $\begin{array}{l}\text { Greeting and playful interactions: "Hi, } \\
\text { J, did you come to play with (X) } \\
\text { today?" "What would you like to play } \\
\end{array}$ \\
& with today?"1 knock it over.
\end{tabular}

Active sensory motor play with a focus on multisensory input

\begin{abstract}
To decrease sensory sensitivities and increase praxis
\end{abstract}

Swinging on space bag and crashing into large pillows and bolsters. Space bag is set low to ground to offset any fear that $J$ might have and to encourage independence during this activity.

Therapist helps J create a "bridge" (two triangular climbing devices with a flat bolster suspended between them). $\mathrm{J}$ climbs up ladder (with assistance), climbs onto bolster, and then jumps into large "crash pad" (pillows). ${ }^{3}$

Snack with a focus on socialization
To decrease sensory sensitivities, improve awareness of body, and increase praxis

To decrease oral sensitivities, expand food repertoire, and enhance socialization
$J$ brings a snack to share with another child. J sets up snack, invites other child, and participates in snack.
Therapist sets up environment with J's needs in mind and then observes child, following the child's cues, to select activity. ${ }^{2}$

Therapist vigilantly observes J's reactions and actions, encouraging $\mathrm{J}$ as needed but allowing for as much self-direction and independence as possible. $^{4}$

Mother packs food and beverage that $\mathrm{J}$ enjoys in addition to one or two foods that $J$ is not familiar with or usually avoids.

Note. OT-SI = occupational therapy with a sensory integration approach. Activities are upgraded and downgraded to meet the child's needs and to ensure success. Therapy is contextualized in sensory-rich play and taps into the child's inner drive for competence (Ayres, 1979). The therapist artfully and skillfully creates enticing, achievable challenges for the child to promote the ability to process and integrate sensory information and observes adaptive responses to these challenges.

'If no response: "I have your favorite game ready. Do you want to play?"

2Upgrade-Add tactile and motor planning component (count to 3 and "crash" into pillows).

3If child is not willing to climb up to bridge, therapist downgrades by lowering bridge.

${ }^{4}$ Therapist uses playful language (singing) or pretend play (climbing into spaceship). 


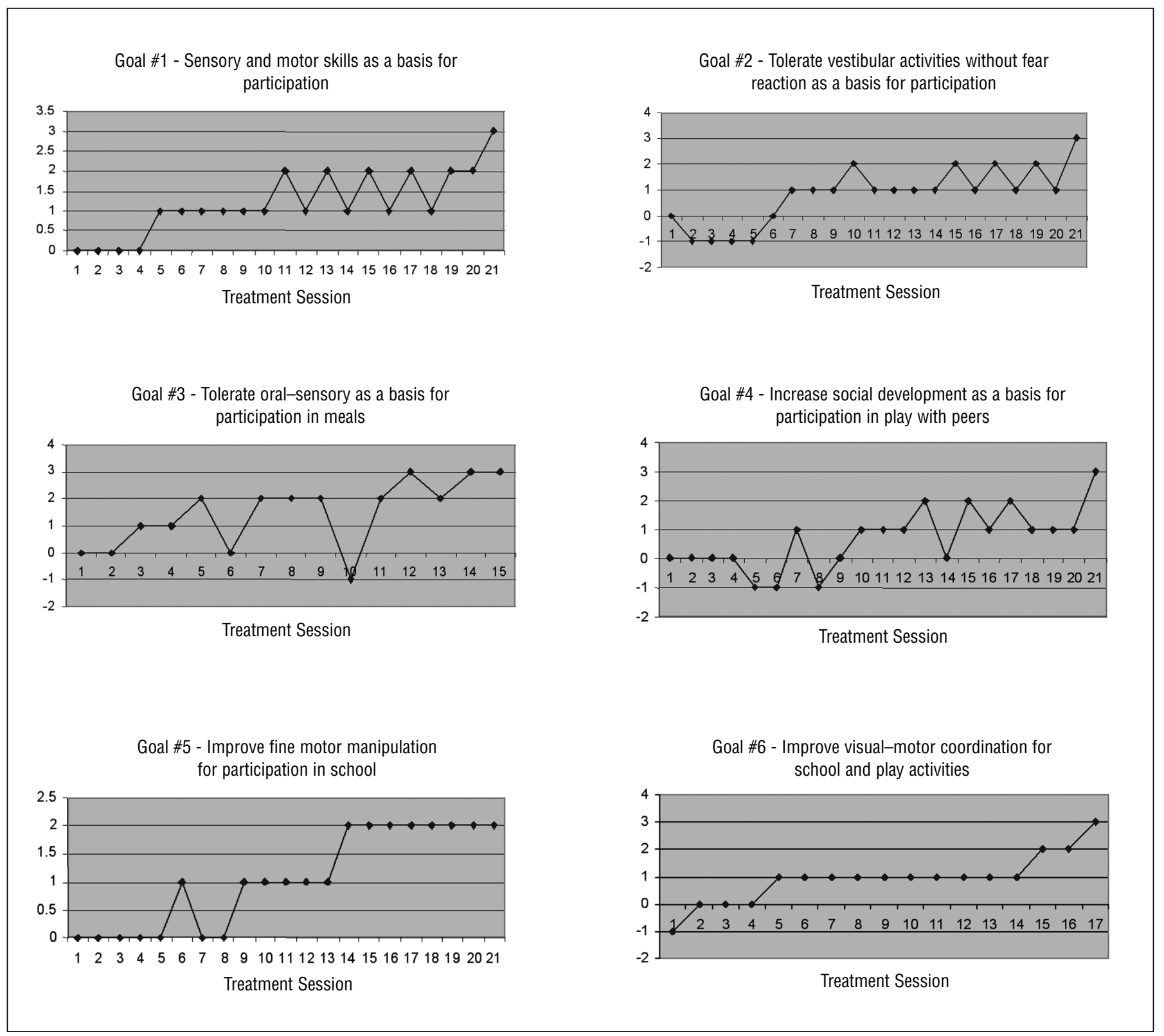

Figure 2. Goals and goal attainment scales. J demonstrated visible improvements in all goals.

\section{Parent Interview}

The parent interview conducted during the final month of occupational therapy services revealed substantial improvements in J's occupational performance and participation. J's mother described how his improvements in sensory processing allowed him to participate in age-appropriate activities more successfully, complete self-care activities independently, socially interact with family and peers more effectively, and perform more successfully in school. She also noted the positive impact these improvements had on their family routines:

$\mathrm{He}$ is [now] able to withstand different textures, tactile/touch things that he wasn't able to before. We are able to go to the beach, and J will play and walk in the sand. He [is doing things now] that originally he said he would never do: go down a slide, climb, jump off something. I get such gratification out of watching him play on the playground ... . he's a totally different kid. ... [Before therapy] he was scared of sound. That was probably one of the things that improved the fastest for him. ... [He] had some pretty noticeable severe sensory issues that I was not educated about before he started his [OT-SI], and the work they have done with him has just been phenomenal. (J's mother, personal communication, July 25, 2002)

Although the Sensory Profile is not designed as a posttest assessment, it was completed after 10 months of intervention as a reassessment tool to determine any further areas of need for J. At this time, J showed typical performance in all but 3 subtests where he showed only a probable difference, suggesting that poor sensory processing was no longer a factor for $\mathrm{J}$. 


\section{Discussion}

This article presents a case study report of a child with poor sensory modulation and occupational performance deficits, and details improvements in occupational performance during 10 months of OT-SI. Most important, this case provides a model of occupational therapy intervention rooted in theory-based clinical reasoning, exemplifying the use of sensory integration theory to address the underlying issues affecting occupational performance and the tenets of occupational therapy practice to guide the assessment, intervention, and outcome measurement. Thus, this report illustrates best practice and a contemporary model for clinical research.

Second, this case contributes to the evidence for using a sensory integrative approach within occupational therapy, demonstrating, as Ayres (1979) intended, the interrelationships among sensory processing, behavior, and occupational performance. Ayres clearly articulated in her theory of sensory integration that inadequate sensory integration affects behavior and development. She stated, "If the brain does a poor job of integrating sensations, this will interfere with many things in life. There will be more effort and difficulty, and less success and satisfaction" (Ayres, 1979, p. 7). Clearly, J's behavior, development, and participation were adversely affected by poor sensory processing, and thus the theory of sensory integration provides the basis for an intervention program.

Last, this case exemplifies a systematic method of data collection and analysis that may be useful in the clinical setting for evaluating outcomes of occupational therapy. We occupational therapists have a professional responsibility to monitor and evaluate our effectiveness. Pressure from outside sources-including funding agencies, administrators, and parents - demand that we demonstrate whether occupational therapy is helping children participate more successfully in their various life environments (e.g., school, home, community), and this case provides a model for doing so.

\section{Limitations}

Although this case provides information that can be useful for clinicians working with children who have poor sensory processing, because it is a case report the results cannot be generalized to the population of children with poor sensory processing. Additional studies are needed to validate the findings. Nevertheless, as suggested by DePoy and Gitlin (1998), this limitation is somewhat offset by the ability of this type of research to provide a guide for clinical practice and to validate theory. A second limitation is related to the validity and reliability of data collection methods. Assessment data relied mainly on parent report, history taking, interview, and chart review and, as such, there is limited objective assessment data. The study would be strengthened by adding newly developed pretest and posttest measures of occupational performance and sensory behaviors such as the Miller Function and Participation Scale (Miller, 2006) (see King et al., in press, for additional suggestions). Finally, best practice includes not only direct intervention, but also thoughtful consideration of the environmental factors that influence behavior and learning, and consideration of the multiple environments in which children participate, and thus this study would be strengthened by greater collaboration with the classroom teacher and adaptations to the classroom environment to facilitate sensory processing and participation.

\section{Acknowledgments}

The second author completed this study as part of her master of science requirements in occupational therapy at Thomas Jefferson University. We thank J for his willingness to play with us and J's mother for her input on this project. Also thanks go to Miles Pustinsky, COTA, who participated in the occupational therapy intervention with the authors. We thank Wilma Dorman, OTR/L, and Occupational Therapy Resources for providing the clinic space. We also thank Teresa A. May-Benson, ScD, OTR/L; Barbara BrettGreen, PhD; Janice P. Burke, PhD, OTR/L, FAOTA; Ellen S. Cohn, ScD, OTR/L, FAOTA; Jane Koomar, ScD, OTR/L, FAOTA; Zoe K. Mailloux, MA, OTR/L, FAOTA; Lucy Jane Miller, PhD, OTR, FAOTA; L. Diane Parham, PhD, OTR/L, FAOTA; Susanne Smith Roley, MS, OTR/L, FAOTA; Sarah A. Schoen, PhD, OTR; and Clare A. Summers, MA, OTR, for contributing ideas about the use of goal attainment scaling in occupational therapy and OT-SI that were used in this article.

\section{References}

American Occupational Therapy Association. (2002). Occupational therapy practice framework: Domain and process. American Journal of Occupational Therapy, 56, 609-639.

Ayres, A. J. (1972). Sensory integration and learning disorders. Los Angeles: Western Psychological Services.

Ayres, A. J. (1979). Sensory integration and the child. Los Angeles: Western Psychological Services.

Cohn, E., Miller, L. J., \& Tickle-Degnen, L. (2000). Parental hopes for therapy outcomes: Children with sensory modulation disorders. American Journal of Occupational Therapy, 54, 36-43.

DePoy, E., \& Gitlin, L. N. (1998). Introduction to researchUnderstanding and applying multiple strategies. St. Louis, MO: Mosby. 
Dunn, W. (1997). The impact of sensory processing abilities on the daily lives of young children and their families. Infants and Young Children, 9(4), 23-35.

Dunn, W. (1999). The sensory profile. San Antonio, TX: Psychological Corporation.

King, G., Law, M., King, S., Hurley, P., Hanna, S., Kertoy, M., et al. (in press). Children's Assessment of Participation and Enjoyment (CAPE) and Preferences for Activities of Children (PAC). San Antonio, TX: Harcourt Assessment.

Kiresuk, T. J., Smith, A., \& Cardillo, J. E. (1994). Goal attainment scaling: Applications, theory and measurement. Hillsdale, NJ: Erlbaum.

Lane, S. J., Miller, L. J., \& Hanft, B. E. (2000, June). Toward a consensus in terminology in sensory integration theory and practice: Part 2: Sensory integration patterns of function and dysfunction. Sensory Integration Special Interest Section Quarterly, 23, 1-3.

Mailloux, Z. K. (2006). Setting goals and objectives around sensory concerns. In R. C. Schaaf \& Smith Roley, S. (Eds.), SI: Applying clinical reasoning to diverse populations (pp. 63-70). San Antonio, TX: Psychological Corporation.

Mailloux, Z. K., May-Benson, T. A., Summers, C. A., Miller, L. J., Brett-Green, B., Burke, J. P., et al. (2007). Goal attainment scaling as a measure of meaningful outcomes for children with sensory integration disorders. American Journal of Occupational Therapy, 61, 254-259.
Miller, L. J. (2003). Empirical evidence related to therapies for sensory processing impairments. NASP Communique, 31(5), 2-5.

Miller, L. J. (2006). Miller Function and Participation Scale. San Antonio, TX: Harcourt Assessment.

Mulligan, S. (2003, June). Examination of the evidence for occupational therapy using a sensory integration framework with children: Part two. Sensory Integration Special Interest Section Quarterly, 26, 1-5.

Ottenbacher, K. J., \& Cusick, A. (1990). Goal attainment scaling as a method of clinical service evaluation. American Journal of Occupational Therapy, 44, 519-525.

Parham, L. D., Cohn, E. S., Spitzer, S., Koomar, J. A., Miller, L., Burke, J. P., et al. (2007). Fidelity in sensory integration intervention research. American Journal of Occupational Therapy, 61, 216-227.

Schaaf, R. C., \& Miller, L. J. (2005). Novel therapies for developmental disabilities: Occupational therapy using a sensory integrative approach. Journal of Mental Retardation and Developmental Disabilities, 11, 143-148.

Schaaf, R. C., \& Smith Roley, S., Eds. (2006). SI: Applying clinical reasoning to diverse populations. San Antonio, TX: Psychological Corporation.

Slavik, E., \& Chew, T. (1990). Design of a sensory integration treatment facility: The Ayres clinic as a model. In S. C. Merrill (Ed.), Environment: Implications for occupational therapy practice: A sensory integrative perspective (pp. 85-101). Rockville, MD: American Occupational Therapy Association.

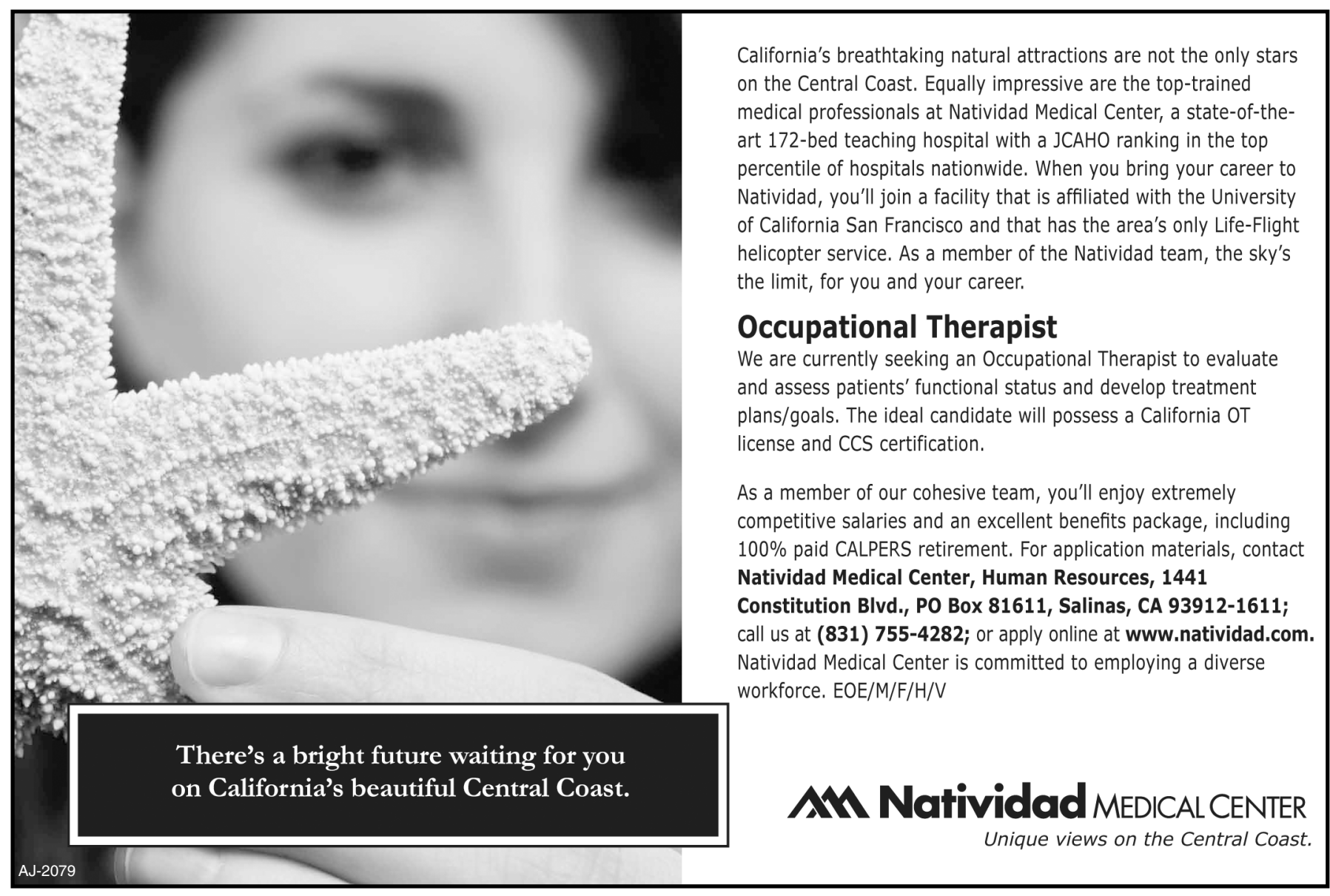

